\title{
The Inclusion of Children with Autism Spectrum Disorders within the Albanian Educational System - A Complex Problem
}

\author{
Ph.D. Geranda Hoxhaj \\ "Kristal" University \\ h.geranda@yahoo.com
}

\section{Doi:10.5901/jesr.2013.v3n7p614}

\section{Abstract}

\begin{abstract}
Parents and pedagogical staff face real challenges because of the alarming growth of cases of Autism Spectrum Disorders, especially of those with symptoms mainly in the cognitive, social, and emotional area. The inclusion of children with ASD-s in normal classrooms, is a complex problem related to the difficulties children display as much as to the deficiency of their psycho-pedagogical treatment. Statistics of the Regional Educational Directorate of Tirana, highlight the fact that there are thirteen autistic pupils who are attending Grade 1 during the academic year 2012-2013. What about the others? It is not easy to define the number of those children who attend school or those who do not, and of those who are integrated into classrooms with normal children. This study is focused on analyzing the factors which influence the exclusion of children with ASDs in the elementary educational system and its consequences. The applied methodology is: study of the literature about education of children with ASDs, focus groups of parents, analysis of statistical data of the Regional Educational Directorate of Tirana. The aim of this study is to bring in facts and arguments about the elements that influence the exclusion of children with ASDs from the educational system, from the point of view of the parent-who has faced to this challenge, and of the schoolmaster- who determines the psycho-pedagogical concerns of the treatment of this category of children, intending to work so as to achieve their inclusion in normal classrooms.
\end{abstract}

Keywords: Autism Spectrum Disorders; Integration; Inclusion; Attendance; Psycho-pedagogical Treatment

\section{Introduction}

"Autism Spectrum Disorder (ASD) is a syndrome that is displayed the first three years of the child's life and it is defined by a form of qualitative abnormalities in communication, social reciprocal interaction and repetitive behaviors" - it is cited in the diagnostically and statistical manual of the American Association of Psychologists (DSM - IV). There are included five various disorders within the term - developmental disorders; these are autism disorders, Asperger's disorder, PDDNOS, Rett`s disorder and childhood disintegrative disorder (CDD). These conditions are referred to as Autism Spectrum Disorders (ASDs). (VOLKMAR et al., 2005)

"The neurobehavioral disorders during childhood are especially defined as social and academic behavioral problems. Dysfunctions have spread considerably since 2007. The Center for Disease Control and Prevention called it a big threat for the health. In fact, it is the most serious threat ever for children's health and well-being; it is reaching epidemic dimensions." (Disconnected Kids. Dr. Robert Melillo. 2010. pg.15)

Autism prevalence seems like growing rapidly every day. In 2009, 1 in 110 children were affected by autism, in 2011, 1 in 88 children, while in 2013 there are 1 in 50 children currently being treated for autism. (https://stopcallingitautism.org /content/presentations/Juan-Rodriguez-SCIA-AutismOne-2013.pdf)

In April 1, 2013, the "New York Times" wrote, "almost 1 in 5 school aged boys (11\% of school aged children) in the United States, were medically diagnosed with attention-deficit hyperactivity disorder, according to the data of federal centers for disease control and prevention."

Despite the possible problematic, children with autism spectrum disorders are educated in classrooms with normal children. Individual treatment is a step by step treatment - from intensive intervention during the first years of their life, special education, to individualized programs for their inclusion in classrooms with normal children. The complexity of dificulties for the inclusion of children with ASDs in normal classrooms in Albania seems like a combination between their disorders and deficiencies in their psycho-pedagogical treatment. Even in Albania, according to the legal rights of education, children with ASDs must be educated in normal classrooms.

The research objectives are exploratory ones. This study aims at exploring the psycho-pedagogical ways of 
treating children with ASDs in normal classrooms, around the world. It aims at exploring the complexity of factors which makes the inclusion of children with autism in normal classrooms more difficult in Albania.

Methodology: this is a qualitative study based on the:

- Study of the literature for the treatment of chidren with ASDs.

- Focus group of parents of children with ASDs.

- Interviews with teachers of children with Autism Spectrum Disorders.

- Analysis of statistcal data of the Regional Educational Directory of Tirana

The research was based on the focus group of parents, as they are a kind of experts of the problematic of children with ASDs. "Focus groups are a new tool of qualitative research." ( Morgan and Spanish "Focus groups: A New Tool of Qualitative Research" 1984). The group consists of eleven parents who have children with ASDs. Their children are between the age of six and ten.

The combination of the semi-structured interview with the focus group of parents, supervision and teachers interviews have served as a tool of research.

\section{The treatment of children with ASD in the developed countries and in Albania}

There are being performed several treatments of children with ASDs, all of which are based in different philosophies but which aim at lightening autism symptoms. Autism treatments have been applied from a long time ago, starting by DR. Ivan Lovaas. He is a pioneer of the Applied Behavioral Analysis to treat children with dramatic disorders in 1960 and 1970, in the University of California, Los Angeles. He was interested in finding ways of lightening self-destructive behaviors and dramatic disorders. From 1980s, students of Dr.Lovaas have worked to find ways of treating children with autism by using various methods. Some of the methods studied with the aim of improving learning of children with autism, were the study of major random learning behaviors by using more interior reinforcement. ( One Step at a Time: ABA and Autism in the Classroom. Jennifer Krumins 2008. Pg. 16)

By the functional evaluation of the relation between the target behavior and environment, ABA methods could be used to change behaviors. (Mulick, James A (early 2006). "Positive Behavior Support and Applied Behavior Analysis". The Behavior Analyst 29 (1): 51-74. Retrieved January 12, 2013). Behavior modification is the traditional term for the use of empirically demonstrated behavior change techniques, to increase or decrease the frequency of behaviors through positive and negative reinforcement. Behavior modification supports positive behavior (PBS, a form of ABA). (Thompson, T. (1984). "The examining magistrate for nature: a retrospective review of Claude Bernard's An Introduction to the Study of Experimental Medicine". Journal of the Experimental Analysis of Behavior 2 (41): 212-13).

While the ABA approach often achieves the child's compliance with its methods, the Miller Method treats the autistic child according to cognitive systems. By system we mean any organized behavior with an object or event that the child produces. Even "upsetting" behaviors-such as throwing or dropping things, opening and closing doors, or lining things up-are systems, although they do not seem to others to serve any particular function. We are interested in such behaviors because they are directed, are organized, and lead to some outcome-all parts of what we look for in functional behavior and in communication. If we can find a way to help the child modify or transform these repetitive action systems so that they become functional and interactive, then we have contributed to the child's development. Communication systems involve the integration of words and actions around objects in relation to another person. Symbolic systems involve the way in which a child organizes the relation between symbols and what they represent. (The Miller Method, Arnold Miller with Kristina Chrétien2007. pg.23)

Dr. Robert Melillo assumes that the problem is brain dysfunction. "Fifty years ago, a hyperactive child was seen as a problem. Today, the deficit attention/hyperactive disorder, generally known as ADHD, is the most widely problem in children's world. In 1973, the concept "Disconnected Kids" is used to explain the symptoms of a so-called condition Alexia that is the inability to read. A functional disconnection does not come as a result of brain impairment. Brain zones, especially brain hemispheres, are not electrically balanced or synchronized. This electric imbalance interferes in the ability of both hemispheres to share information. This means that the brain can not work as an entire part. The Brain Balancing Program is based on a technique called the hemispheric integration therapy (HIT). First of all, a child was given several tests to evaluate his/her symptoms and functional skills so as to define the problematic hemisphere and its functioning. Moreover, several daily activities - sensory, physical and academic - were chosen for a direct impact on the problematic areas. At first, these activities were applied one at a time, to strengthen functional weaknesses and then, all of them were applied together to integrate large areas of the brain, especially both hemispheres, and to synchronize them." (Disconnected Kids. Dr. Robert Melillo. 2010. Fq. 210) 
Although treatments were conceptualized and performed by corresponding specialists and therapists from genuine schools, the level of these treatments' efficiency in children with ASDs is still ambiguous.

The semi-structured questions for the focus group refer to this trend: What kind of therapy did the child attend? What education did the therapist attend? Which principles is the treatment based upon? Who are the responsible people for individual therapy? What are the positive changes as a result of this treatment?

By the information given by the focus group it was stated that: in Albania it is performed mainly the developmental therapy. Sometimes they try to derive elements from ABA therapy or the Floortime approach. Therapists were not educated by a genuine school for the treatment of autistic children. They obtain a general psychological culture, or they have attended school subjects but not an oriented therapy according a certain philosophy. Parents are not introduced to the principles upon which the child treatment is based. In most cases repetition of the same activities until the child performs it is the methodology of work. From the parent point of view, that is hopeless. The therapist is the only person who works with the child, and consequently she/he is the head of the treatment and also responsible for it. Most of the parents had switched from one therapist to the other, without noticing any improvements on account of the individual treatment. Other parents had noticed that the child did the same activities with the therapist as with them or with the teacher in normal classrooms.

\section{Early treatment and timing- as an important element of the development of children with ASDs}

Those young children with autism that are fortunate enough to receive it, are trained in an intensive format (20-40 hours per week) by one or more trained therapists, supervised by Behavior Analysts and overseen by a behavioral psychologist. Early educational programs consist of the relation between cause and effect, development and attention and imitating skills. This early intervention, if it is done with the needed proficiency, paves the way for the child to learn more about the world and his/her country. The early intervention tries to treat these areas: the relation between cause and effect, concentration and imitating. Usually, infants use their senses to explore the environment, to experiment with people, toys and objects. This is the base of learning. Autistic children have not shown interest or capacity in this kind of exploration. They should learn how to understand and experiment. ( One Step at a Time: ABA and Autism in the Classroom 2008 Jennifer Krumins. pg. 16-22 )

Decades of research have shown that behavioral therapies for autism can improve cognitive and language skills. Still, it remained unclear whether behavioral interventions simply reduced autism's symptoms or actually "treated" the developmental disorder. In other words, could an effective behavioral intervention change the brain biology that underlies autism spectrum disorder? This year, researchers delivered compelling evidence that the Early Start Denver Model (ESDM), an intensive early intervention program for toddlers with autism, improves brain activity related to social responsiveness. The Journal of the American Academy of Child \& Adolescent Psychiatry published: "This may be the first demonstration that a behavioral intervention for autism is associated with changes in brain function as well as positive changes in behavior". This more-typical pattern of brain activity was associated with improved social behavior including improved eye contact and social communication. "The more you teach a child to become involved within the social interaction, the more it can lead to normal brain and behavioral development." ( Dawson G, Jones EJ, Merkle K, et al. Early behavioral intervention is associated with normalized brain activity in young children with autism. 2012; 51(11):1150-9).

Could the early intervention in children with ASDs be performed in Albania? If yes, how?

Our focus group makes us clear that many of them have tried to perform the early intervention therapy, but they have come across several challenges. Firstly, we lack specialists which could give the correct evaluation of the specific diagnosis within the autism spectrum - according to which it can be planed the intervention. Secondly, the undertrained specialist executes the same scheme of intervention for all kids, without taking into account their specific skills. Thirdly, it seems like the need for therapy exceeds the capacity of institutions or therapists available, and consequently it is impossible to extend therapies more than one hour per day or week (referring to state institutions). Fourthly, it is difficult for the parent to afford more than one hour of therapy as the price is high. As mentioned above, it seems that the early intervention therapy is inefficient because of the way of performing and because of the inability to apply it in the needed timing.

\section{Disorders` elements - difficult to be trained within educational environment}

Disorders` elements such as: hyperactivity, lack of concentration, stereotypes, aggressiveness, self-aggressiveness and 
the inability to control ones emotions are some of the most difficult elements of to be treated or managed by the teacher in normal classrooms.

"Most children do not feel their own bodies very well. They have no sense of themselves in space. They have poor or abnormal muscle tone, which is displayed through poor posture or an awkward gait. They are disconnected from their senses. Most children with disorders do not fully experience all five senses- sight, hearing, touch, taste, and smell-which teach normal children to relate to and interact within the world. Many of these children cannot use more than one sense at a time. When they are forced to use multiple senses together, they become overwhelmed. They become easily distracted by anything they can see, hear, or feel, which make it impossible for them to focus. As a result, they become like slaves to their environment. They are socially and emotionally disconnected." (Disconnected Kids. Dr. Robert Melillo. 2010. pg.20)

"While manifesting most of the problematic behaviors, could it be aggressive behavior, the child with ASDs does not intend to hurt others. On the other hand, these behaviors come as a result of the disability to take control of their emotions, including confusion, anger and anxiety. These behaviors must not be interpreted as malicious ones. Often, if they are depressed, it is difficult for children with ASDs to discipline ones emotions. So are they. That does not mean, "Do not stress the child". That means that the child must be taught how to face to stress or keep calm. This would be the greatest present for him/her. Often, the stress factor in classrooms is one of these: language, social or school requirements are too high (or this might be the child's perception); violation of expectations of the child, including frequent and unexpected changes of routine. The child with ASDs cannot withstand the noisy, messy or full of light environment, which seems nice and funny to normal children." (Autism in your classroom. Deborah Fein, Ph. D \& Michelle. Dunn, Ph. D 2007. pg. 284)

During interviews, teachers answered that they are not ready to enable the inclusion of children with ASDs in their classrooms, because they are not trained to analyze or intervene in them to manage behaviors of children with ASDs.

"Behaviors are really difficult to be managed if the staff does not have as much information as possible. The possibility to discuss the problems' solution with the parents and professionals is done to get the opinion of people working with these children. Each person working directly with the child knows one part of the puzzle- every opinion put together creates the whole photo. The teacher needs the whole puzzle to become an effective educator." ( One Step at a Time: ABA and Autism in the Classroom 2008 Jennifer Krumins. pg. 23 )

Difficulties of the inclusion of children with autism spectrum disorders in classrooms with normal children in Albania represent a challenge for parents and teachers. The only help seems to be the cooperation between teacher and parent. Open communication between them faces another conceptual barrier, as a result of lack of information or prejudice influence.According to the focus group of parents, the close link between parent and teacher, led the way to hopeful cases when children have achieved to attend the school environment. In absence of relevant structures that had the task to evaluate needs, make up individual plans and supervise children`s with ASDs performances, the cooperation is very important.

\section{Teaching in pupils with Autism Spectrum Disorders.}

How does autism impact on learning? Autism is a complex developmental disability that affects how an individual thinks, learns and experiences the world. All children with autism are different but they share difficulties in five core areas. These include: Communication, Social Interaction, Repetitive Behavior/Restricted Interests, Sensory Processing, and Information Processing/Learning Style. (http://www.autismtraining.com)

Team work is the right way to train children in school environment. The team of professionals that attends the autistic child during the treatment consists of: Behavior Analysts, Speech and Language, Therapists, Occupational Therapists, Teachers, SENCOs, Educational Psychologists. Each professional plays his own role for an effective treatment of autism. (UK ABA Autism Education Competence Framework November 2011 pg. 78)

Playing, as an important element for the emotional and social area, could be used as a means of help by the educator for the inclusion of pupils with ASDs. "Some children, for various reasons, do not have a natural approach to playing - and children with autism, among others, belong to this group. Children with autism find it difficult to interact socially with one another - and consequently they are often seen as children who cannot learn to play with others. But if the play is organized by grown-ups on the child`s terms, the children find a common platform where - through play - they can gain social experiences, which otherwise can be difficult for them to obtain." (Autism, Play and Social Interaction Lone Gammeltoft and Marianne Sollok Nordenhof 2007 pg.10,)

According to teachers' interviews it was stated that the teacher stands alone before the pupil with ASDs. In fact, 
there does not exist a real team to treat the child within the school environment. There is only one psychologist who has to cover problems of tow thousand pupils, but who cannot contribute to the treatment of pupils with ASDs.

\section{Involvement, inclusion or attendance!?}

It is important to make it clear if the presence of children with ASDs within the school environment means that, he/she gets involved together with normal children by being part of educational activities; if he/she has been accepted as part of the group of normal children, or he/she is just present without getting involved within educational or other activities. This was one of the issues of discussion of the focus group.

From the data collected by the focus group of parents of children from 6 to 10 years old,- primary school age, (Table 1) - we notice that:

\begin{tabular}{|c|c|c|c|}
\hline $\begin{array}{c}\text { The overall No. of } \\
\text { children }\end{array}$ & $\begin{array}{c}\text { No. of kindergarten } \\
\text { children }\end{array}$ & $\begin{array}{c}\text { No. of preschool } \\
\text { children }\end{array}$ & $\begin{array}{c}\text { No. of first grade children, primary } \\
\text { school }\end{array}$ \\
\hline 11 (6-10 years old $)$ & 7 (6-10 years old $)$ & $2(8-9$ years old $)$ & 2 (9-10 years old $)$ \\
\hline
\end{tabular}

Table 1.

Parents thought that the term that best fitted their children was "Attendance". Attendance was the best opportunity offered to them.

Even teachers expressed that, in fact, children with ASDs, are just present, without trying to get involved in activities or perform learning tasks.

Referring to the Regional Educational Directory of Tirana, for the elementary cycle for the academic year 2012 2013(Table 2), we notice that:

\begin{tabular}{|c|c|c|}
\hline The overall No. of pupils within the elementary cycle & 23915 & \\
\hline No. of autistic pupils & 61 & $0.2 \%$ \\
\hline
\end{tabular}

Table 2.

If we notice the statistics in percentage, the results show that the percentage of autism prevalence among elementary school children is very low. But, how real is that?

If the percentage given in the table would show us the prevalence of autism within this age of children, autism dimensions then, would not be as worrying as they really are.

Even though this is a qualitative study, our focus group has answered this question. The majority of children with ASDs could not get involved within classrooms with normal children. Only two children with ASDs out of 11 could attend classrooms with normal children.

Why don't other children with ASDs attend educational environment? This is another question asked to the group of focus. Parents and teachers argue that behavioral disorders, especially: hyperactivity, lack of concentration, aggression, and stereotypes are symptoms that the teacher can not manage alone. Assistance is not offered and the parent is not allowed to assist his/her child because of the lack of legal basis.

\section{Results of the exclusion of children with ASDs from educational environment.}

What does it mean to live with autism? - it is another question for the focus group of parents. Parents range several problems which accompany the living with disorder, from the psychological shock when of parents when they notice abnormal signs of development, the hopeless diagnosis, facing the disorder every day, the inability to help the child with the right treatment to the exclusion from schooling, as the only one way to get closer to normality. The first years go by, hoping for a better treatment, or by thinking "he/she is still a little child, he/she will change". As the child need a person to accompany him/her or the impossibility to attend school, the mother, necessarily, becomes an unemployed person and the family faces big psychological and financial problems. 


\section{Results}

According to data collected from the focus group of parents and from interviews with teachers can be stated that: The inclusion of children with autism spectrum disorders within the Albanian educational system faces several problems related to the problematic of the disorders and also faces the lack of the psycho-pedagogical infrastructure that is offered by the educational system.

Lack of early treatment and lack of efficient treatment during the following years of these children's life, lead them unprepared toward primary school's fundamental elements, that would help them understand and perform learning tasks and social relations.

The untrained teacher feels unable to treat the child with ASDs as a result of lack of information about the phenomenon and not knowing how to treat it. Moreover, the teacher faces alone to the disorders manifested by the child, without the assistance of a professional.

It seems like the problematic that affects even the family of the child with autism spectrum disorder is leading to a growing progression the number of people who suffer autism consequences.

Exclusion from school environment is the last alienation from reality for the child with ASDs and for his/her family.

\section{References}

Volkmar et al., 2005 https://stopcallingitautism.org/content/presentations/Juan-Rodriguez-SCIA-AutismOne-2013.pdf

Nju York Times, April 1, 2013

Morgan and Spanish "Focus groups; A New Tool for Qualitative Research" 1984

Mulick, James A (early 2006). "Positive Behavior Support and Applied Behavior Analysis". The Behavior Analyst 29

Thompson, T. (1984). "The examining magistrate for nature: a retrospective review of Claude Bernard's An Introduction to the Study of Experimental Medicine". Journal of the Experimental Analysis of Behavior 2

The Miller Method, Arnold Miller with Kristina Chrétien2007

Dawson G, Jones EJ, Merkle K, et al. Early behavioral intervention is associated ëhhoith normalized brain activity in young children with autism. 2012

Disconnected Kids. Dr. Robert Melillo. 2010

Autism in your classroom. Deborah Fein, Ph. D \& Michelle. Dunn, Ph. D 2007, http://www.autismtraining.com.

UK ABA Autism Education Competence Framework November 2011

Autism, Play and Social Interaction Lone Gammeltoft and Marianne Sollok Nordenhof 2007

One Step at a Time: ABA and Autism in the Classroom Jennifer Krumins. 2008 